\title{
Extraction, Phenolic Content and Hydrogen Peroxide Scavenging Capacity of Extracts from Some Honey Samples, Propolis and Bee Pollen
}

\author{
Zohra Mohammedi \\ Department of Biology, Faculty of Natural Sciences and Life, University of Mustapha Stambouli, \\ BP 305 Street of Mamounia, Mascara 29000, Tel: 0551724433, Algeria. \\ Corresponding author \\ mdi3zhr@gmail.com
}

Manuscript received: 01 October, 2020. Revision accepted: 24 June, 2021. Published: 16 July, 2021.

\begin{abstract}
Honey and propolis is natural food, produced by honey bees (Apis mellifera) and largely used by the local population for its medicinal properties. Our work aims to extract and evaluate the hydrogen peroxide scavenging capacity of different phenolic extracts from some bee products. Phenolic compounds from honey samples, propolis, and bee pollen were extracted by methanol and subjected to radical scavenging activity towards hydrogen peroxide. The results showed the highest values for the total phenolic and total flavonoïd contents in propolis and bee pollen, and a great hydrogen peroxide $\left(\mathrm{H}_{2} \mathrm{O}_{2}\right)$ inhibition (IC50: $0.205-2.210 \mu \mathrm{g} / \mathrm{mL}$ ) with honey extracts, while sample "multiflower" is the better antioxidant, more than ascorbic acid used as control. The less scavenging activity was observed with the extract from bee pollen (IC50: $39.383 \mu \mathrm{g} / \mathrm{mL}$ ). To combat the harmful effects of free radicals, especially reactive oxygen species including hydrogen peroxide, it is important to use phenolic extracts instead of using honey as it is, and extracts from the honey of different types are excellent antioxidants compared to other bee products.
\end{abstract}

Keywords: Apis mellifera; honey; propolis; phenolic compounds; hydrogen peroxide.

\section{INTRODUCTION}

Honey is the nectar collected and processed from different plants by honey bees (Apis mellifera) and is known for its high nutritional value (An et al., 2016). It has been used in many cultures for its medicinal properties, as a remedy for burns, cataracts, ulcers and wound healing, because it exerts a soothing effect when initially applied to open wounds. According to its origin, honey can be classified in different categories: blossom honey, honeydew honey, monofloral honey, and multifloral honey that has several botanical sources (Alvarez-Suarez et al., 2014). Honey is composed of approximately $82.4 \%$ total carbohydrates (Almasaudi et al., 2017). The polyphenols constitute minor components of honey (Istasse et al., 2016).

Honey has been reported to promote numerous nutritional and biological effects, such as antioxidant, antimicrobial, antiviral, antiparasitic, anticancer, antiinflammatory, and immunosuppressive activities (Duddukuri et al., 1997; Othman, 2012; Shahzad and Cohrs, 2012; Borsato et al., 2014; Samarghandian et al., 2017; Sowa et al., 2017; Sinha et al., 2018). However, the antioxidant properties of honey are well known because it contains a number of compounds with antioxidant properties such as polyphenols, amino acids, ascorbic acid, and some enzymes. The most important classes of antioxidants are the phenolic acids and flavonoids (Ayoub et al., 2009). They have a promising effect on the treatment of some chronic diseases (Isla et al., 2013). A wide range of phenolic constituents in honey are known such as gallic acid, syringic acid, vanillic acid, benzoic acid, chlorogenic acid, ferulic acid, protocatechuic acid, 3-O-caffeoylquinic acid, phydroxybenzoic acid, 5-O-caffeoylquinic acid, caffeic acid, p-coumaric acid, ellagic acid, dihydroxybenzoic acid methyl ether, benzyl caffeate, protocatechualdehyde, gentisic acid, vanillin, sinapic acid, salicylic acid, dihydrocinnamic acid, 2,2,4trihydroxybenzoic acid, hesperetin, naringin, naringenin, hesperidin, tricetin, myricetin, quercetin, quercitrin, quercetin 3-orhamnoside, kaempferol 3-orhamnoside, kaempferol 7-orhamnoside, luteolin, pinobanksin 5methyl ether, naringenin, apigenin, kaempferol, methoxy-kaempferol, pinobanksin, isorhamnetin, chrysoeriol, rhamnetin, chrysin, sakuranetin, pinocembrin, galangin, kaempferide, acacetin, morin, tangeretin, catechin, genistein, ectochrysin, and other compounds such as caffeic acid phenethyl ester, Kojic acid, 5-hydroxymethylfurfural, dehydrovomifoliol, leptosin, glyoxal, methylglyoxal, 3-deoxyglucosulose (An et al., 2016; Alvarez-Suarez et al., 2014; Isla et al., 
2013; Lachman et al., 2010; Cianciosi et al., 2018; Cheung et al., 2019; Nešovíc et al., 2020).

Another bee product is propolis, which is a resinous substance collected by honeybees from various plant sources. This natural product has been used for thousands of years in folk medicine for several purposes and contains amino acids, terpenes, tannins, polysaccharides, phenolic acids, phenolic acid esters, cinnamic acid, caffeic acid, phenethyl caffeate, pcoumaric acid and flavonoids such as kaempferol, naringin, chrysin, and galangin. Propolis possesses several biological activities such as anti-inflammatory, immunostimulatory, antiviral, and antibacterial. Propolis extract and its active components showed strong antioxidant activities, a free radical scavenging effect, a significant inhibition of xanthine oxidase activity, ferric reducing antioxidant power, and an anti-lipoperoxidative capacity (Russo et al., 2002; Kumazawa et al., 2004; Korayem et al., 2012; Socha et al., 2015).

A large number of studies have estimated the antioxidant activities of honey by a range of methods (DPPH free radical scavenging activity, ABTS radical cation decolorization assay, FRAP assay, ORAC assay, etc.), but the step of dilution is a major drawback in antioxidant tests since it generates a toxic oxidant substance $\left(\mathrm{H}_{2} \mathrm{O}_{2}\right)$, the cause of the exclusion by researchers of the antioxidant test by hydrogen peroxide scavenging activity in entire honey. So, the aim of this study was to extract phenolic and flavonoids compounds, then evaluate the antioxidant activity of obtained extracts from different types of honey against hydrogen peroxide, and to compare with two phenolic extracts from propolis and bee pollen. Also, we highlight the ability of the phenolic compounds in honey to eliminate hydrogen peroxide, and therefore the step of extraction of polyphenols is important in the context of the use of honey in the fight against oxidative stress.

\section{MATERIALS AND METHODS}

\section{Bee products}

Honey samples (Multiflower and monofloral honey: Eucalyptus, Thyme, Sidr, Citrus, and Epins honey), Propolis and Bee pollen are the local products of Tlemcen, Algeria.

The $100 \%$ natural honey samples from Apis mellifera were obtained directly from the beekeeper in 2019 from different vegetation sources in Tlemcen city. These honey samples were chosen for their quality, in terms of low content of water and hydroxymethylfurfural (HMF).

\section{Extraction of phenolic compounds from honey samples}

The extraction of phenolic compounds from the honey samples was performed according to the method described by An et al. (2016). The stationary phase of the glass column, Amberlite XAD-2 resin, was prepared by soaking $100 \mathrm{~g}$ of Amberlite XAD-2 resin in methanol. The packed column was washed successively with acidified distilled water followed by neutral distilled water. The honey sample was diluted with acidified water and loaded into the packed glass column. Sugars were eliminated with hydrochloric acid solution and water washes. Phenolics compounds were desorbed with methanol and then dried at $50^{\circ} \mathrm{C}$ using a Rotavapor. The dried product was protected from light and stored at $5^{\circ} \mathrm{C}$ until use.

\section{Extraction of phenolic compounds from propolis and bee pollen}

For extract phenolic compounds from propolis and bee pollen samples, the hydroalcoholic solutions (methanolwater) were used. For each $5 \mathrm{~g}$ sample, $100 \mathrm{~mL}$ of methanol $80 \%$ were added, the mixture was covered with aluminum paper and then filtered after $24 \mathrm{~h}$. The filtrates were dried at $50^{\circ} \mathrm{C}$ using a Rotavapor. The dried extracts were stored at $5^{\circ} \mathrm{C}$ until use.

\section{Total phenolic contents}

The total phenolic contents of honey samples, propolis, and bee pollen extracts were analyzed by the FolinCiocalteu method (Singleton et al., 1999) using gallic acid as a standard. The methanolic solution of each sample of honey, propolis, bee pollen, and gallic acid was prepared. The test samples and standard solutions of different concentrations were introduced into separate test tubes. Folin-Ciocalteu reagent, diluted in water (1:1), and $\mathrm{Na}_{2} \mathrm{CO}_{3}$ saturated solution were added. The tubes were vortexed, incubated in the dark at room temperature for 25 minutes and then the absorbance was read at $725 \mathrm{~nm}$ against the blank using a spectrophotometer. The total phenolic content was determined by comparison with a calibration curve of gallic acid and represented as $\mathrm{mg}$ gallic acid equivalents per 100 gram (mgGAE/100g).

\section{Total flavonoid content}

The total flavonoïd content was determined by the $\mathrm{AlCl}_{3}$ method (Cottica et al., 2011) using rutin as standard. $250 \mu \mathrm{L}$ of $\mathrm{AlCl}_{3} 5 \%(\mathrm{~m} / \mathrm{v}$ in methanol) were added to separate test tubes containing the methanolic solution of each honey sample, propolis, bee pollen extracts, and rutin solutions of different concentrations. After $30 \mathrm{~min}$ incubation at room temperature, the absorbance was read at $425 \mathrm{~nm}$ using a spectrophotometer. The total flavonoid content was determined by comparison with the calibration curve of the rutin and represented as $\mathrm{mg}$ rutin equivalents per 100gram (mgRE/100g).

\section{Antioxidant activity (Hydrogen peroxide scavenging activity)}

The hydrogen peroxide scavenging activity was measured by the method described by Ruch et al. (1989). A volume of $0.6 \mathrm{~mL}$ of the solution of hydrogen 
peroxide $(0.089 \mathrm{mM})$, prepared in phosphate buffer (0.1M, pH 7.4) was added in a series of test tubes, containing $3.4 \mathrm{~mL}$ phenolic extract solutions (3$10 \mu \mathrm{g} / \mathrm{mL}$ ) from honey samples, propolis, bee pollen and standard (ascorbic acid). The percentage of hydrogen peroxide scavenging activity was calculated by the formula:

\section{$\%$ Scavenged $\left[\mathrm{H}_{2} \mathrm{O}_{2}\right]=[(\mathrm{AC}-\mathrm{AT}) / \mathrm{AC}] \times 100$}

Where AC is the absorbance of the control and AT is the absorbance in the presence of the phenolic extracts from different samples (tests) and standard.

\section{Statistical analysis}

The results of experiments were expressed as (mean \pm $\mathrm{SD} ; \mathrm{n}=3$ ), and subjected to statistical analysis at $95 \%$ confidence level $(\mathrm{p}<0.05)$ by student's t-test using GraphPad Prism software.

\section{RESULTS AND DISCUSSION}

The results of phenolic content and flavonoid content were reported in table 1 . Total phenolic content in six honey samples was ranged from $4.36 \mathrm{mgGAE} / 100 \mathrm{~g}$ to $26.29 \mathrm{mgGAE} / 100 \mathrm{~g}$ honey, with the average value of $12.755 \mathrm{mgGAE}$ per $100 \mathrm{~g}$ honey. The Multiflower type of honey was the sample containing a high amount of phenolic compounds and the monofloral type "Citrus" honey was the sample with the lowest quantity of phenolic compounds compared to all honey samples. The same observation was showed in flavonoid content. The Multiflower type remains the richest honey in phenolic compounds compared to other honey. While the lowest content is also observed in the "Citrus" type. The flavonoids content obtained was from $1.95 \pm 0.352$ $\mathrm{mgRE} / 100 \mathrm{~g}$ to $10.65 \pm 1.020 \mathrm{mgRE} / 100 \mathrm{~g}$, with an average amount of $4.607 \mathrm{mgRE}$ per $100 \mathrm{~g}$ honey. The evaluated results were in close agreement with the results reported by Meinen et al. (2014), which have reported that total phenolic content is ranged between $8.114 \mathrm{mg}$ and $109 \mathrm{mg}$ per $100 \mathrm{~g}$ honey and for the total flavonoid content is ranged between $0.655 \mathrm{mg}$ and 212 $\mathrm{mg}$ per $100 \mathrm{~g}$ honey. This study was perfected in 30 honey samples. Boulanouar et al. (2017) have observed higher levels of phenolic compounds in two types of Algerian honey, which are $38 \pm 0.009 \mathrm{mgGAE} / 100 \mathrm{~g}$ for the type "Zizyphus" and $86 \pm 0.008 \mathrm{mgGAE} / 100 \mathrm{~g}$ for the type "Harmala", whereas for the flavonoids, they found contents, which belong to the range of values that we recorded, the values of flavonoids were $5 \pm 0.003$ $\mathrm{mgRE} / 100 \mathrm{~g}$ and $8 \pm 0.002 \mathrm{mgRE} / 100 \mathrm{~g}$ for "Zizyphus" and "Harmala" types, respectively. Also, the same remark is observed with the works of Khalil et al. (2012). These authors analyzed four samples of Algerian honey and registered mean values of $45.983 \pm 0.192$ $\mathrm{mg} / 100 \mathrm{~g}$ for phenolic compounds and values of 5.423 $\pm 0.062 \mathrm{mg} / 100 \mathrm{~g}$ for flavonoids.

Table 1. Total Phenol content and flavonoids of honey samples, propolis and bee pollen.

\begin{tabular}{lll}
\hline \multirow{2}{*}{ Sample } & $\begin{array}{l}\text { Average amount } \\
\text { of phenolic }\end{array}$ & $\begin{array}{l}\text { Average amount } \\
\text { of flavonoids }\end{array}$ \\
\cline { 2 - 3 } (mgGAE/100g) & mgRE/100g \\
\hline Multiflower honey & $26.29 \pm 9.764^{\mathrm{a}}$ & $10.65 \pm 1.020^{\mathrm{a}}$ \\
Thyme honey & $8.67 \pm 2.494^{\mathrm{b}}$ & $2.61 \pm 0.558^{\mathrm{b}}$ \\
Citrus honey & $4.36 \pm 2.441^{\mathrm{c}}$ & $1.95 \pm 0.352^{\mathrm{b}}$ \\
Eucalyptus honey & $8.97 \pm 1.033^{\mathrm{b}}$ & $2.21 \pm 1.068^{\mathrm{b}}$ \\
Sidr honey & $14.20 \pm 3.278^{\mathrm{d}}$ & $5.31 \pm 0.112^{\mathrm{c}}$ \\
Epins honey & $14.04 \pm 4.260^{\mathrm{d}}$ & $4.91 \pm 0.232^{\mathrm{c}}$ \\
Propolis & $9161.0 \pm 6.906 \mathrm{e}$ & $2189.62 \pm 1.975^{\mathrm{d}}$ \\
Bee pollen & $4794.15 \pm 6.169^{\mathrm{f}}$ & $1267.38 \pm 0.912^{\mathrm{e}}$ \\
\hline
\end{tabular}

Data are (Mean $\pm S D, n=3$ ).

Means within a column sharing the same letter are not significantly different by Student's $t$-test $(P<0.05)$.

Total phenol and flavonoids were also compared to the values reported for the honey from different countries. Some authors have found results, approaching our range of values, such as the work of Reshma et al. (2016), Almasaudi et al. (2017) and Krpan et al. (2009). The first authors have shown that the phenolic content in 24 samples of honey was ranged between $20.2 \pm 1.2$ $\mathrm{mg} / 100 \mathrm{~g}$ to $30.78 \pm 2.5 \mathrm{mg} / 100 \mathrm{~g}$, the second authors have observed that the high total phenolic content was $10.399 \pm 0.168 \mathrm{mg} / 100 \mathrm{~g}$ in "Manuka" type of honey and the lowest phenolic content was $9.6 \pm 0.002 \mathrm{mg} / 100 \mathrm{~g}$ for "Sidr" type of honey, while the third authors have ranged the total phenolic content from $3.172 \mathrm{mg} / 100 \mathrm{~g}$ to $8.011 \mathrm{mg} / 100 \mathrm{~g}$ honey and this later study was performed only in one type of honey, which is the "Acacia" type. In contrast, other authors have deferred high and even very high levels, for examples, for Chua et al. (2013) the total phenolic content of honey samples was in the narrow range from 110.394 to $196.500 \mathrm{mgGAE} / 100 \mathrm{~g}$, ARahaman et al. (2013) showed that the total phenolic contents for honey samples were ranged from 38.379 to $60.617 \mathrm{mg}$ GAE/100g, Pontis et al. (2014) ranged the total phenolic content from 25 to $54.8 \mathrm{mg}$ gallic acid per $100 \mathrm{~g}$ of honey, while for Buba et al. (2013), the mean values of total phenolic content are around $65.31 \pm$ $19.50 \mathrm{mg}$ gallic acid equivalent per $100 \mathrm{~g}$. In addition, some authors have reported very small quantities of phenolic content in honey, for example, Ferreres et al. (1994) reported 0.50 to $2.0 \mathrm{mg}$ per $100 \mathrm{~g}$ honey. For flavonoids, Pontis et al. (2014) have shown less content than obtained in our studies, the total flavonoid content was ranged from 0.9 to $4.86 \mathrm{mg}$ per $100 \mathrm{~g}$ honey.

The results obtained experimentally in table 1 show very high levels of phenolic compounds and flavonoïds in propolis and bee pollen compared to those obtained in honey samples and the amount of phenolic and 
flavonoids in propolis was higher than bee pollen. The quantities registered in propolis and bee pollen were $9161.0 \pm 6.906 \mathrm{mgGAE} / 100 \mathrm{~g}, \quad 4794.15 \pm 6.169$ $\mathrm{mgGAE} / 100 \mathrm{~g}$ for total phenolic content and $2189.62 \pm$ $1.975 \mathrm{mgRE} / 100 \mathrm{~g}, 1267.38 \pm 0.912 \mathrm{mgRE} / 100 \mathrm{~g}$ for total flavonoids content, respectively. Boulanouar et al. (2017) have also observed that propolis contains more phenolic and flavonoïds than honey, the respective quantities registered were $2385 \pm 2.90 \mathrm{mgGAE} / 100 \mathrm{~g}$ and $379 \pm 0.54 \mathrm{mg} \mathrm{RE} / 100 \mathrm{~g}$. Čeksteryte et al. (2016) have also observed high levels of phenolic compounds in bee pollen, but are less relative to the quantities we have obtained. The values of total phenolic content found were $2330 \mathrm{mg} \mathrm{GAE} / 100 \mathrm{~g}$.

The antioxidant capacity of honey and bee products is due mainly to the phenolic compounds. The samples exhibited various antioxidant activity measured towards hydrogen peroxide, which is concentration-dependent (figure 1). Results show that the scavenging activity values on hydrogen peroxide of phenolic extracts from honey samples were more efficient than other bee products. Lower antioxidant activity was observed in extracts from propolis and bee pollen.

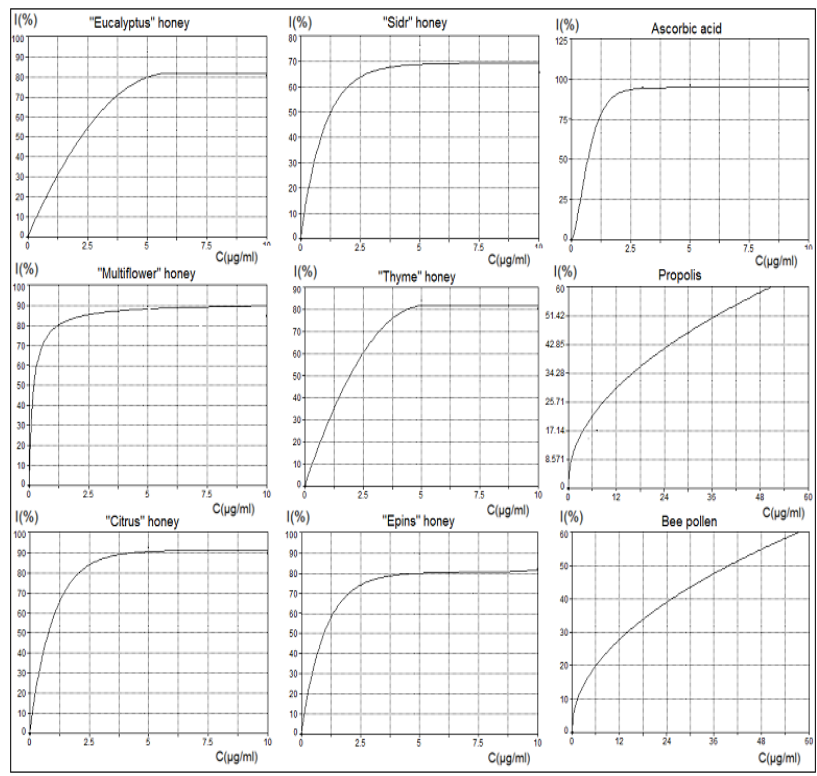

Figure 1. Hydrogen peroxide $\left(\mathrm{H}_{2} \mathrm{O}_{2}\right)$ scavenging activity of phenolic extract from honeys, propolis, bee pollen, and ascorbic acid.

The antioxidant activity of honey has been reported in many scientific works (Krpan et al., 2009; Pontis et al., 2014; Reshma et al., 2016; Chua et al., 2013; ARahaman et al., 2013). Currently, some very limited research on antioxidant activity has been conducted on phenolic extracts of honey (Lianda et al., 2012; Bridi et al., 2017; Estevinho et al., 2008; Halagarda et al., 2020), but no research has assessed the capacity of extracts or phenolic fractions isolated from honey by the hydrogen peroxide scavenging method. Hydrogen peroxide is not very reactive, but it can be toxic because it may produce hydroxyl radicals in the cells. Thus, removing $\mathrm{H}_{2} \mathrm{O}_{2}$ is very important in the cell. The scavenging ability of honey samples, propolis, and bee pollen was examined by comparing to that of the known antioxidants Ascorbic acid. The extract of honey type "multiflower" showed powerful activity on hydrogen peroxide and decreases its concentration more than the positive control, ascorbic acid. Antioxidant activity, expressed as IC50 (Table 2) was $0.206 \pm 0.0243 \mu \mathrm{g} / \mathrm{mL}$, while the standard given an IC50 value of $0.694 \pm 0.0238 \mu \mathrm{g} / \mathrm{mL}$. This parameter IC50 defined the concentration of the sample, which scavenge $50 \%$ of hydrogen peroxide. The sample with lower IC50 presents potent antioxidants. The phenolic extracts from extracts of others honey types exhibited also a good antioxidant activity on $\mathrm{H}_{2} \mathrm{O}_{2}$. The scavenging ability is in the following order: "Multiflower" > Ascorbic acid > "Citrus" > "Epins" > "Sidr" > "Thyme" > "Eucalyptus". It has been reported that the antioxidant capacity of honey was correlated with the biochemical constituents, in particularly with phenolic compounds and flavonoids (Chua et al., 2013; Buba et al., 2013).

Table 2. Hydrogen peroxide scavenging capacity of phenolic extract from honey samples, propolis and bee pollen, expressed as IC50 $(\mu \mathrm{g} / \mathrm{mL})$.

\begin{tabular}{ll}
\hline Extract & IC50 $(\boldsymbol{\mu g} / \mathbf{m L})$ \\
\hline Multiflower honey & $0.206 \pm 0.0243^{\mathrm{a}}$ \\
Thyme honey & $1.928 \pm 0.0209^{\mathrm{b}}$ \\
Citrus honey & $0.771 \pm 0.0239^{\mathrm{c}}$ \\
Eucalyptus honey & $2.211 \pm 0.0216^{\mathrm{d}}$ \\
Sidr honey & $1.259 \pm 0.0224^{\mathrm{e}}$ \\
Epins honey & $0.951 \pm 0.0099^{\mathrm{f}}$ \\
Propolis & $35.116 \pm 0.4049^{\mathrm{g}}$ \\
Bee pollen & $39.383 \pm 0.2622^{\mathrm{h}}$ \\
Ascorbic acid & $0.694 \pm 0.0238^{\mathrm{i}}$ \\
\hline
\end{tabular}

Data are (Mean $\pm S D, n=3$ ).

Means within a column sharing the same letter are not significantly different by Student's t-test $(P<0.05)$.

Poor scavenging activity is observed with extracts from propolis $(35.116 \mu \mathrm{g} / \mathrm{mL})$ and bee pollen $(38.383$ $\mu \mathrm{g} / \mathrm{mL}$ ). In similar studies, the $\mathrm{H}_{2} \mathrm{O}_{2}$ scavenging assay of phenolic compounds extracted from propolis by various solvents (distilled water, absolute methanol, 50\% methanol, and $70 \%$ methanol) presented different action on $\mathrm{H}_{2} \mathrm{O}_{2}$, which IC50 values were between $11.72 \mu \mathrm{g} / \mathrm{mL}$ and $765.75 \mu \mathrm{g} / \mathrm{mL}$ (Farooq Wali et al., 2016; Ramnath et al., 2016; Kizılpınar Temizer et al., 2017). Although these two bee products are quantitatively rich in phenolic compounds, but their extracts have a low antioxidant capacity compared to honey extracts, which suggests that the antioxidant capacity is not always dependent on the amount of phenolics and flavonoids, honeys are therefore a good source of antioxidant substances. Also, the botanical origins of honey greatly influence hydrogen peroxide scavenging capacity. The results of the IC50 obtained in table 2 clearly confirm these observations. 


\section{CONCLUSION}

In this present study, it had been established that phenolic extracts from all types of honey, propolis, and bee pollen contain phenolic and flavonoids compounds and possessed antioxidant property toward hydrogen peroxide, and therefore the preventive and medical application of phenolic extracts from honey, and other bee products against oxidative stress are recommended. All honey types after extraction of phenolic compounds are able to scavenge efficiently the hydrogen peroxide, and this capacity is as much greater than that observed in other bee products. Antioxidant activity against $\mathrm{H}_{2} \mathrm{O}_{2}$ in honey samples is related to botanical type, which is strongly affected by the floral origin, and therefore varies quantitatively and qualitatively with the content of antioxidant phenolic compounds. It is well shown in the results that extract from "multiflower" honey has a content of phenolic substances with good antioxidant power against hydrogen peroxide. It is important to identify and quantify the phenolic compounds in honey extract from this type.

\section{REFERENCES}

Almasaudi SB, Al-Nahari AAM, Abd El-Ghany ESM, Barbour E, Al-Muhayawi SM, Al-Jaouni S, Azhar E, Qari M, Qari YA, Harakeh S (2017) Antimicrobial effect of different types of honey on Staphylococcus aureus. Saudi Journal of Biological Sciences 24: 1255-1261.

Alvarez-Suarez JM, Gasparrini M, Forbes-Hernández TY, Mazzoni L, Giampieri F (2014) The Composition and Biological Activity of Honey: A Focus on Manuka Honey. Foods 3: 420-432.

An CY, Hossain MM, Alam F, Islam MA, Khalil MI, Alam N, Gan SH (2016) Efficiency of Polyphenol Extraction from Artificial Honey Using C18 Cartridges and Amberlite, XAD2 Resin: A Comparative Study. Journal of Chemistry ID 8356739: 1-6.

A-Rahaman NL, Chua LS, Sarmidi MR, Aziz R (2013) Physicochemical and radical scavenging activities of honey samples from Malaysia. Agricultural Sciences 4: 46-51.

A-Rahaman NL, Chua LS, Sarmidi MR, Aziz R (2013) Physicochemical and radical scavenging activities of honey samples from Malaysia. Agricultural Sciences 4: 46-51.

Ayoub SMH, Makawi SZA., Gadkariem EA (2009) Determination of antioxidant flavonoids in sudanese honey samples by solid phase extraction and high performance liquid chromatography. E-Journal of Chemistry 6: S429-S437.

Borsato DM, Prudente AS, Döll-Boscardin PM, Borsato AV, Luz CFP, Maia BHL, Cabrini DA, Otuki MF, Miguel MD, Farago PV, Miguel OG (2014) Topical Anti-Inflammatory Activity of a Monofloral Honey of Mimosa scabrella Provided by Melipona marginata During Winter in Southern Brazil. J Med Food 17: 817-825.

Boulanouar B, Mounir H, Ahmed B, Abdelaziz G (2017) Total Phenolic, Flavonoid Contents and Antioxidant Activities of Honey and Propolis Collected from the Region of Laghouat (South of Algeria). Int J Pharmacogn Chinese Med1: 1-4.
Bridi R, Nuňez-Quijada G, Aguilar P, Martínez P, Lissi E, Giordano A, Montenegro G (2017) Differences between phenolic content and antioxidant capacity of quillay Chilean honeys and their separated phenolic extract. Cen Inv Agr 44: 252-261.

Buba F, Gidado A, Shugaba A (2013) Analysis of Biochemical Composition of Honey Samples from North-East Nigeria. Biochem Anal Biochem 2: 2-7.

Čeksterytė V, Kurtinaitienė B, Venskutonis RP, Pukalskas A, Kazernavičiūtė R., Balžekas J (2016) Evaluation of Antioxidant Activity and Flavonoid Composition in Differently Preserved Bee Products. Czech J Food Sci 34: 133-142.

Cheung Y, Meenu M, Yu X, Xu B (2019) Phenolic acids and flavonoids profiles of commercial honey from different floral sources and geographic sources. Int J Food Prop 22: 290-308.

Chua LS, Rahaman NL, Adnan NA, Tan TTE (2013) Antioxidant Activity of Three Honey Samples in relation with Their Biochemical Components. Journal of Analytical Methods in Chemistry ID313798: 1-8.

Chua LS, Rahaman NL, Adnan NA, Tan TTE (2013) Antioxidant Activity of Three Honey Samples in relation with Their Biochemical Components. Journal of Analytical Methods in Chemistry ID313798: 1-8.

Cianciosi D, Forbes-Hernández TY, Afrin S, Gasparrini M, Reboredo-Rodriguez P, Manna PP, Zhang J, Lamas LB, Flórez SM, Toyos PA, Quiles JS, Giampieri F, Battino M (2018) Phenolic Compounds in Honey and Their Associated Health Benefits: A Review. Molecules 23: 1-20.

Cottica SM, Sawaya ACHF, Eberlin MN, Franco SL, Zeoulae LM, Visentainera JV (2011) Antioxidant Activity and Composition of Propolis Obtained by Different Methods of Extraction. Journal of the Brazilian Chemical Society 22: 929935.

Duddukuri GR, Kumar PS, Kumar VB, Athota RR (1997) Immunosuppressive effect of honey on the induction of allergen-specific humoral antibody response in mice. Int Arch Allergy Immunol 114: 385-388.

Estevinho L, Pereira AP, Moreira L, Dias LG, Pereira E (2008) Antioxidant and antimicrobial effects of phenolic compounds extracts of Northeast Portugal honey. Food Chem Toxicol 46: 3774-3779.

Farooq Wali A, Mushtaq A, U-Rehman M, Akbar S, Masoodi MH (2016) In vitro antioxidant and antimicrobial activities of propolis from Kashmir Himalaya region. Free Rad Antiox 6: 51-57.

Ferreres P, Andrade P, Tomás-Barberán FA (1994) Flavonoids from Portuguese heather honey. Zeitschrift f ur LebensmittelUntersuchung und -Forschung 199: 32-37.

Halagarda M, Groth S, Popek S, Sascha R, Pedan V (2020) Antioxidant Activity and Phenolic Profile of Selected Organic and Conventional Honeys from Poland. Antioxidants 9: 1-19.

Isla M, Cordero A, Díaz L, Pérez-Pérez EM., Vit P (2013) Cosmetic properties of honey. 1. Antioxidant activity. In: Vit P, Roubik DW (eds) Stingless bees process honey and pollen in cerumen pots. Facultad de Farmacia y Bioanálisis, Universidad de Los Andes, Mérida, Venezuela.

Istasse T, Jacquet N, Berchem T, Haubruge E, Nguyen BK, Richel A (2016) Extraction of Honey Polyphenols: Method Development and Evidence of $\mathrm{Cis}$ Isomerization. Anal Chem Insights 11: 49-57.

Khallil MI, Moniruzzaman M, Boukraâ L, Benhanifia L, Islam MA, Islam MN, Sulaiman SA, Gan SH (2012) 
Physicochemical and Antioxidant Properties of Algerian Honey. Molecules 17: 11199-11215.

Kızılpınar Temizer I, Güder A, Gençay Çelemli Ö (2017) Botanical origin and antioxidant activities of propolis from the Irano-Turanian region. Istanbul J Pharm 47: 107-111.

Korayem AM, Khodairy MM, Abdel-Aal AA, El-Sonbaty AAM (2012) The protective strategy of antioxidant enzymes against hydrogen peroxide in honey bee, Apis mellifera during two different seasons. J Biol Earth Sci 2: B93-B109.

Krpan M., Marković K., Šarić G., Skoko B., Hruškar M., Vahčić N (2009) Antioxidant Activities and Total Phenolics of Acacia Honey. Czech J Food Sci 27: S245- S247.

Kumazawa S, Hamasaka T, Nakayama T (2004) Antioxidant activity of propolis of various geographic origins. Food Chemistry 84: 329-339.

Lachman J, Hejtmánková A, Sýkora J, Karban J, Orsák M, Rygerová B (2010) Contents of Major Phenolic and Flavonoid Antioxidants in Selected Czech Honey. Czech J Food Sci 28: 412-426.

Lianda RLP, Sant Ana LO, Echevarria A, Castro RN (2012) Antioxidant activity and phenolic composition of brasilian honeys and their extracts. J Braz Chem Soc 23: 618-627.

Meinen N, Camilleri L, Attard E (2014) The Antioxidant Activity of Maltese Honey. J Apic Sci 58: 51-60.

Nešovíć $M$, Gašić U, Tosti T, Trifković J, Baošić R, Blagojević $S$, Ignjatović L, Živoslav T (2020) Physicochemical analysis and phenolic profile of polyfloral and honeydew honey from Montenegro. Rsc Adv 10: 2462-2471.

Othman NH (2012) Does Honey Have the Characteristics of natural cancer vaccine? J Tradit Complement Med 2:276-283.

Pontis JA, Costa LAM, Silva SJR, Flach A (2014) Color, phenolic and flavonoid content, and antioxidant activity of honey from Roraima, Brazil. Food Sci Technol 34: 69-73.

Ramnath S, Venkataramegowda S (2016) Antioxidant Activity of Indian Propolis - An In Vitro Evaluation. IJPPE 5: 79-85.
Reshma MV, Shyma S, George TM, Rishin AV, Ravi KC, Shilu L (2016) Study on the physicochemical parameters, phenolic profile and antioxidant properties of Indian honey samples from extrafloral sources and multi floral sources. International Food Research Journal 23: 2021-2028.

Reshma MV, Shyma S, George TM, Rishin AV, Ravi KC, Shilu L (2016) Study on the physicochemical parameters, phenolic profile and antioxidant properties of Indian honey samples from extrafloral sources and multi floral sources. International Food Research Journal 23: 2021-2028.

Ruch RJ., Cheng SJ., Klaunig, JE (1989) Prevention of cytotoxicity and inhibition of intracellular communication by antioxidant catechins isolated from Chinese green tea Carcinogenesis 10: 1003-1008.

Russo A, Longo R, Vanella A (2002) Antioxidant activity of propolis: role of caffeic acid phenethyl ester and galangin. Fitoterapia 73: S21-S29.

Samarghandian S, Farkhondeh T, Samini F (2017) Honey and Health: A Review of Recent Clinical Research. Pharmacognosy Res 9: 121-127.

Shahzad A, Cohrs RJ (2012) In vitro activity of honey against varicella virus (VZV): A translational medicine study for potential remedy for shingles. Transl Biomed 3: 1-7.

Singleton VL, Rudolf O, Rose LR (1999) Analysis of total phenols and other oxidation substrates and antioxidant by means of Folin-Ciocalteu reagent. Methods Enzymology 299: $152-178$.

Sinha S, Prakash A, Sehgal R, Medhi B (2018) Comparative effect of manuka honey on anaerobic parasitic protozoans with standard drug therapy under in vitro conditions: Apreliminary study. Indian J Pharmacol 50:197-203.

Sowa P, Grabek-Lejko D, Wesolowska M, Swacha S, Dzugan M (2017) Hydrogen peroxide-dependent antibacterial action of Melilotus albus honey. Lett Appl Microbiol 65: 82-89. 